\title{
Perceptual and lexical priming of syntactic construction in young children
}

\author{
Meesook Kim \\ Department of English Language and Literature, Sangji University, Korea \\ https://doi.org/10.36505/ExLing-2011/04/0022/000191
}

\begin{abstract}
Two experiments are reported to investigate the roles of perceptual priming and lexical priming in Korean children's production of passive sentences. Experiment 1 examined whether manipulations of focal attention could affect Korean children's linguistic choices regarding subject role assignment, by using so-called fish film (Tomlin, 1997). 5-year-olds and 6-year-olds were not able to produce passives even when a patient was perceptually primed by a flashing arrow. Experiment 2 examined lexical priming effects in children's production of passives. 5-year-olds and 6-yearolds were more likely to use passive sentences if a patient has been verbally primed by the experimenter. These results indicate that young children's production of passive voice is more likely to be affected by linguistic cues than perceptual salience.
\end{abstract}

Keywords: focal attention, language acquisition, lexical priming, passives

\section{Introduction}

When do speakers make a decision of using passive sentences? A common answer for this question is that speakers may use passives to topicalize the patient in an event, by promoting it to syntactic subject (Dik, 1989; Langacker, 1990). For instance, in the full passive sentence like The cat was chased by the dog, the focus is on the cat and what happened to it, rather than on the dog's act of chasing as in the active description of this event. Accordingly, if we could manipulate speakers' attention on the patient, then they would be able to use the passive construction frequently. How can we manipulate speakers/hearers' attention on the patient in an event?

One possibility is that perceptual cues or factors play a crucial role in word order or constituent. Specifically, research on the perceptual salience has shown that perceptual factors like size and color are clearly involved in ordering simple conjoined noun phrases (e.g. A bear and a dog) (Gleitman, Gleitman, Miller \& Ostrin, 1996; Osgood \& Bock, 1977). In addition, the role of perceptual salience has been empirically tested by Tomlin (1997), by using the so-called fish film in on-line production task. Tomlin finds a close relationship between primed referents and subject role assignment. However, the role of perceptual salience in constituent order still remains unclear because some studies find no relationship between initially fixated stimuli and subject role assignment (Griffin \& Bock, 2000).

ExLing 2011: Proceedings of 4th Tutorial and Research Workshop on Experimental Linguistics, 25-27 May, Paris, France 
Another possibility is that linguistic cues like lexical or syntactic priming play a crucial role in subject role assignment. For instance, a preceding stimulus like a particular word or sentence increases the likelihood that the speaker will produce an identical word or sentence. In addition, some researchers have argued that in the early stages of syntactic development children have lexically-based word patterns rather than general grammatical form (Olguin \& Tomasello, 1993; Tomasello, 2000).

In this paper, two experiments were designed to investigate the role of perceptual salience as well as lexical priming effects in Korean children's production of passive sentences, by using the fish film designed by Tomlin (1997). First, if the experimental manipulation of focal attention affects subject assignment in voice alternation, we expect that it will also be confirmed if tested using data from language acquisition. Therefore, the present study extends Tomlin's (1997) experimental paradigm of attention manipulation to language acquisition, by testing Korean children aged 5 to 6 . Another experiment was used to investigate whether linguistic cues like lexical priming would affect children's sentence production in subject role assignment. In this experiment, a preceding stimulus like a lexically-primed referent (either agent or patient) will be heard to each participant. Accordingly, the linguistic Priming tool predicts that Korean-speaking children will be more likely to produce the reference as syntactic subject when they hear the experimenter's sentence.

\section{Experiments}

\section{Experiment 1: Perceptual priming paradigm}

Participants

Twenty 5-year-old children (age range $=5: 3-5: 11$, Mean=5:6) and twenty 6year-old children (age range=6:2-6:11, Mean=6:8) participated in this experiment.

Materials and Procedure

The experimental materials used in the perceptual priming task were similar to the original fish film designed by Tomlin (1997). However, the present study modified fish film by using a different size of fish, in order to focus on the saliency of the perceptual priming. The experimental framework in the present study consists of a production task where subjects are to produce online descriptions of a sequence of 20 events. It shows two computeranimated fish swimming towards each other until they meet and one of them eats the other and swims off the screen. 
Results

Table 1. Number and Percentage of Utterances by Each Age Group: Perceptual Priming Paradigm

\begin{tabular}{|l|c|c|c|c|}
\hline \hline & \multicolumn{2}{|c|}{ Agent-Primed(AP) } & \multicolumn{2}{c|}{ Patient-Primed(PP) } \\
\cline { 2 - 5 } & Active & Passive & Active & Passive \\
\hline 5-year olds & $200(100 \%)$ & $0(0 \%)$ & $190(95 \%)$ & $10(5 \%)$ \\
\hline 6-year olds & $200(100 \%)$ & $0(0 \%)$ & $182(91 \%)$ & $18(9 \%)$ \\
\hline
\end{tabular}

\section{Experiment 2: Lexical priming task \\ Participants}

Twenty 5-year-old children (age range=5:0-5:11, Mean=5:5) and twenty 6year-old children (age range $=6: 0-6: 10$, Mean=6:6) participated in this experiment. They were recruited from daycare centers in the Wonju area.

\section{Materials and procedure}

The experimental materials used in the production task were the same as those used in the perceptual paradigm. That is, like Experiment 1, Experiment 2 also used a fish-film which consisted of twenty events. Unlike Experiment 1, the second experiment enforced the child to produce either active or passive sentences by priming a lexical word. For instance, after showing each event of the film to the child, the experimenter asked "what's happening [What happened] to X" where X was the patient or the agent of a transitive action. Focusing on the child's attention on the patient by priming a lexical word may create a pressure to produce a passive sentence because the child may be more likely to put the patient in the subject position (Brooks \& Tomasello, 1999; Marchman, Bates, Burkardt, \& Good, 1991).

\section{Results}

Table 2. Number and Percentage of Utterances by Each Age Group: Lexical Priming Paradigm Result

\begin{tabular}{|l|c|c|c|c|}
\hline \hline & \multicolumn{2}{|c|}{ Agent-Primed(AP) } & \multicolumn{2}{c|}{ Patient-Primed(PP) } \\
\cline { 2 - 5 } & Active & Passive & Active & Passive \\
\hline 5-year olds & $199(99.5 \%)$ & $1(0.5 \%)$ & $144(72 \%)$ & $56(28 \%)$ \\
\hline 6-year olds & $200(100 \%)$ & $0(0 \%)$ & $115(57.5 \%)$ & $85(42.5 \%)$ \\
\hline
\end{tabular}

\section{Conclusion}

Taken together, the results of these two experiments clearly demonstrate that there is a relationship between linguistic priming and children's production of passive voice, whereas there is no direct relationship between attention and language production. Further investigation will be necessary to examine the role of perceptual salience in children's sentence production, by manipulating various perceptual cues like colour or size. In addition, further 
investigation will be necessary to examine the effects of experimental manipulations of visual attention, by using various verbs for describing visual scenes. Using various verbs for describing an event will allow us to take a closer look at children's developmental patterns of passive voice.

\section{References}

Bock, K. 1986. Meaning, sound, and syntax: Lexical priming in sentence production. Journal of Experimental Psychology: Learning, Memory, and Cognition 12, 575-586.

Bock, K. 1990. Structure in language: Creating from in talk. American Psychologist 45, 1221-1236.

Bock, K., Loebell, H., Morey, R. 1992. From conceptual roles to structural relations: Bridging the syntactic cleft. Psychological Review 99, 150-171.

Gleitman, L., Gleitman, H., Miller, C., Ostrin, R. 1996. Similar and similar concepts. Cognition 58, 321-376.

Griffin, Z.M., Bock, J.K. 2000. What the eyes say about speaking. Psychological Science 11, 274-279.

Huttenlocher, J., Vasilyeva, M., Shimpi, P. 2004. Syntactic priming in young Children. Journal of Memory and Language 50, 182-195.

Olguin, R., Tomasello, M. 1993. Twenty-five-month-old children do not have a grammatical category of verb. Cognitive Development 8, 245-272.

Osgood, C., Bock, J. 1977. Salience and sentencing: Some production principles. In S. Rosenberg (Ed.), Sentence production: Developments in research and theory (pp. 89-140). Hillsdale, N.J.: Erlbaum.

Tomlin, R. 1997. Mapping conceptual representations into linguistic representations: The role of attention in grammar. In N. Jan \& P. Eric (Eds.), Language and conceptualization (pp. 162-189). Cambridge: Cambridge University Press. 